\title{
Analysis of The Role of Competitive Benchmarking on Service Delivery in Multinational Pharmaceutical Companies in Nairobi City County, Kenya
}

\author{
Betty Mukiri Murerwa*, Godfrey Muigai Kinyua \\ School of Business, Kenyatta University, Nairobi, Kenya
}

*Corresponding Authors: Betty Mukiri Murerwa, School of Business, Kenyatta University, Nairobi, Kenya

\begin{abstract}
The study sought to investigate the role of competitive benchmarking on service delivery of multinational pharmaceutical firms in Nairobi City County, Kenya. Market penetration and market growth were the indicators used to measure competitive benchmarking, while the dependent variable service delivery was measured by reliability, assurance, responsiveness and affordability. The study adopted the descriptive research design. The population of the study was 128 employees in the senior and middle level managerial positions in the pharmaceutical firms. Census technique was incorporated which allowed the inclusion of the whole target population in the survey. Structured questionnaires were used as tool for primary data collection. SPSS software was used in the analysis of quantitative data through the descriptive statistics. Simple linear regression analysis was run to determine the level of association between the independent and dependent variables. The analyzed data was presented in form of mean, standard deviation and coefficient of variations. Findings from the analysis revealed that competitive benchmarking had a positive yet statistically insignificant effect on service delivery of the multinational pharmaceutical firms in Nairobi City County, Kenya. The study recommended for similar study to be conducted in different industry.
\end{abstract}

Key words: Competitive benchmarking and Service Delivery.

\section{INTRODUCTION}

The role of pharmaceutical firms in the ever changing global economy is indisputable. The pharmaceutical industry plays the important role of constant production, development and marketing of medication to clients in need of these services. In the Africa, there has been increased growth in the pharmaceutical market, with an increase in the number of pharmaceutical firms in individual countries (Chorey, 2019). The African drug market has been of importance in terms of service delivery and is considered to be the one to save lives in African countries in the next years to come (World Bank, 2016).

Success of the pharmaceutical firms is mainly determined by the level of competition from other firms and practitioners (Hadland, Aguirre, Marshall \&Cerdá, 2019). The strategies adopted by firms make it possible for them to keep up with the existing level of competition which is normally very high, this in turn helps them maintain their position in the competitive industry of service production (Cole, 2018). In africa, one child loses his life every half a minute due to sickness, an outbreak of malaria in South Africa saw a rise in the number of pharmaceutical firms, which proves the importance of the firms in combating diseases (Tannoury\&Attieh, 2017).

Kenyan Pharmaceutical industry has a high level of competition and was featured by wars in prices (Kenya Economic Survey, 2017). This comes as a result of an increased level of investment in the pharmaceutical industry making it a lucrative business. Government policies dictate the price structure given out by the multinational pharmaceutical firms (Otieno, 2014). As a strategy for remaining relevant in the industry, these firms thus have to adopt strategies which act as their tools for survival (Hadlandet al, 2019). For this reason, the study aimed to investigate how competitive benchmarking influenced service delivery of multinational pharmaceutical firms in Nairobi City County. As per 
Elmuti and Kathawala (2012), benchmarking is a very necessary process that needs to be performed by the multinational pharmaceutical firms in Kenya to ensure effective service delivery.

Service delivery, is an immediate output of the inputs incorporated in the multinational pharmaceutical system. It encompasses the satisfaction of customers both tangible and intangible (Kothari, 2013). Service delivery in pharmaceutical firms in Kenya is one of the significant contributors to their success (Mailu, Ntale\&Ngui, 2018). Compliance with the regulations set by regulators such as the Pharmacy and Poisons Board is one of the crucial ways that has made the multinational pharmaceuticals offer appropriate service delivery to the consumers. The other measure of service delivery is the time for delivery of the pharmaceutical products to the clients.This has enabled the clients to rely and build trust on the pharmaceutical company.

The pharmaceutical firms have to incorporate benchmarking strategies like competitive benchmarking in an effort of improving the quality of their service delivery.Companies use competitive benchmarking to gauge their successes and pinpoint their shortcomings (Sexana, 2011). The main objective of competitive benchmarking is to make comparison of firms whose products and services compete in the same market space. The indicators used to measure competitive benchmarking were market share, growth in sales, and customer base.Other literature that support competitive benchmarking as a factor for service delivery include (Kinyua, 2015; Abdullahi \& Kinyua, 2018; Gabow\& Kinyua, 2018; Kobia\& Kinyua, 2018; Karanja, Muraguri\& Kinyua, 2018).

According to Kenya Medical Suppliers Agency (KEMSA, 2017), multinational pharmaceutical firms in Kenya comprise of manufacturers and producers. They have a labor force of more than 3500 personnel, with $60 \%$ being in direct production. $90 \%$ of the multinational pharmaceutical firms are based in Nairobi with the remaining 10\% distributed in other parts of the country. Up until 2020, the pharmaceutical industry in Kenya was worth US\$ 500Milion (KEMSA, 2020). However, according to a report given out by Pharmacy and Poisons Board in September 2017, it was realized that it was necessary for improvements to be made on the service delivery measures by both the local and multinational pharmaceutical firms based in Kenya.

Maintaining better accessibility, availability of quality drugs and increased revenue translates to excellent service delivery (Owouth 2010). Proliferation of counterfeit and unregulated medical drugs is of the hindrance to the achievement of Kenyan Universal Health Care according to a statement issued by the Kenya Association of Pharmaceutical Industry, KAPI,(2018).The pharmaceutical industry in Kenya was undergoing major changes which included shrinking margins, changes in demographics, emerging markets and rapid changes in technology (Kenya Healthcare Federation \& Taskforce Healthcare, 2016). The high technology innovative products were quite high for most of these firms to market. The strategies set by organizations are greatly affected by these rapid changes, which in turn affect the quality of service that the firms offer to their clients.

Findings from previous studies on competitive benchmarking include Otieno (2013) affirmed the significance of competitive benchmarking among the hotelier industry in Kenya; Jenifer and Allan (2017) concluded that competitive benchmarking had a significant effect on the performance of manufacturing firms in Nairobi City County; Ouma (2018) assessed the factors critical for success of pharmaceutical firms, the researcher concluded that competitive benchmarking was one of th factors considered key in performance of the pharmaceutical firms. Other studies that were done in Kenya were done many years back while others were done outside Kenya. The aim of the research was assessing effect of competitive benchmarking strategies on service delivery offered by multinational Pharmaceutical Firms in Nairobi, Kenya.

\section{LITERATURE REVIEW}

\subsection{Serviqual Model}

The model can also be referred to as the RATER model. It was developed and implemented in the mid-1980s by academic researchers Zeithaml, Parasuraman and Berry. RATER which is an acronym standing for reliability, assurance, tangibles, empathy, and responsiveness represents. The model helps to best describe the different modes of service delivery and the service quality experienced by customers (Kumar, 2013). 
This initial aim of the model was for use by the service providing firms to help them in providing a more structured service which would influence the consumers' perception about the firm positively. Whilst several firms are keen on rendering customer service, the measure of service quality is only vital to firms in the service industry, which need to not only understand but also be aware of the measures used in the assessment of the quality of service. Serviqual model, therefore, attempts to describe in a wider scope the elements of quality service provision rather than focusing on modest service delivery measures (Law, 2014).

Serviqual model illustrates the fact that the quality of service offered by a firm is the bridge between customers' expectations for the service offered and the perception of the service actual received (Ayele, 2012). As the model measures the attitude of perceived service opposed to the actual service offered, thus cannot clearly depict satisfaction. Customer gap is the main notable difference existing expectations of customers and their perceptions. Mendy (2016) states that customer expectations is what the customer sees themselves getting out of a firm based on the available resources, influenced by cultural background, lifestyle, personality, advertising and experience with similar products. According to Newman (2001), in spite of the controversies concerning the validity and reliability of serviqual, its application can be found in healthcare. Therefore, this model was used to anchor service delivery as the independent variable.

\subsection{Empirical Literature Review}

Georges (2014) conducted an investigation on the effect of competitive benchmarking on the service delivery of Coffee companies in Nigeria. While using correlation as well as regression analysis, findings indicated that effective implementation of competitive benchmarking has an effect on performance of coffee firms that is both positive and significant. In addressing contextual gaps, this research focused on the Pharmaceutical Firms in Nairobi City County, Kenya.

Kerandi,Nyaoga, Bosire and Nyambega (2014), investigated service delivery strategies improvement through benchmarking in commercial banks in Kenya. They also sought to investigate the relationship existing between benchmarking strategies and the methods of service delivery, and the challenges faced when implementing competitive benchmarking. It was deduced that in general, benchmarking had a statistically significant and positive effect on service delivery of organizations. Recommendation for a study to be carried in the future to monitor the correlation of benchmarking with organizational service delivery and performance was made.

Twaissi and Alhelalat(2015), conducted a research on benchmarking strategies in the tourism sector in Petra, Jordan. The findings revealed that benchmarking strategies had significant effect on performance of the tourism sector. It was conclude that it was important for tourism companies to adopt benchmarking strategies like competitive and functional benchmarking. Recommendation made was for other researchers to investigate other factors that could affect performance of the sector.

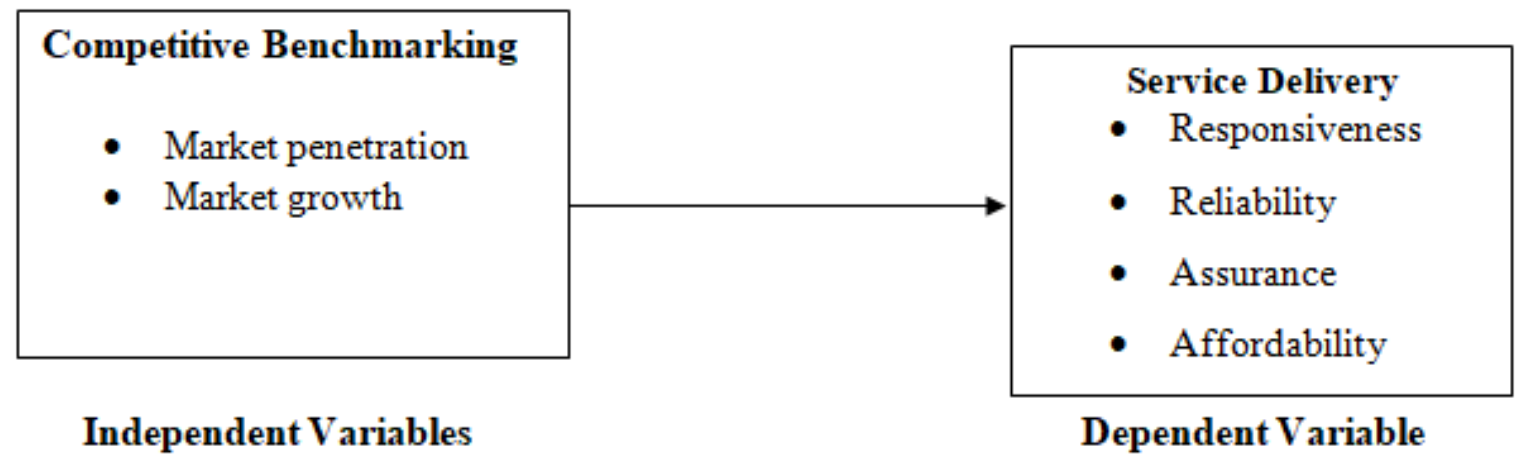

Figure1.Conceptual Framework

Source: Researcher (2020)

Therefore, from the developed conceptual framework, the research objective for the study became;

Toestablishthe effect of competitive benchmarking on service delivery in Multinational
Pharmaceutical Firms in Nairobi City County, Kenya. 


\section{RESEARCH METHODOLOGY}

According to Creswell (2014), a research design is a framework that a researcher chooses to help in tackling the research problem at hand. For the study, the descriptive research design was employed. The design was chosen as it is better placed to give accurate information (Mugenda \& Mugenda, 2013). The descriptive design made it possible to collect data on competitive benchmarking strategy and service delivery in multinational pharmaceutical firms in Nairobi City County, Kenya. It would help explain the phenomenal relationship between external benchmarking and service delivery in multinational pharmaceutical firms in Nairobi City County, Kenya over other research designs. The descriptive research design has also been found relevant with other researchers. It has been used in various studies by researchers like (King'oo, Kimencu\& Kinyua, 2020; Kung'u, Kahuthia\& Kinyua, 2020; Gatuyu\& Kinyua, 2020; Muthoni \& Kinyua, 2020; Ontita\& Kinyua, 2020; Mbugua \& Kinyua, 2020).

The study's population comprised of pharmaceutical companies in Nairobi City County. The target population comprised of management employees from multinational pharmaceutical companies based in Nairobi County. These firms included; GlaxoSmithKline (GSK) pharmaceuticals, Betta Healthcare International, Bayer East Africa, Roche pharmaceuticals, Sanofi, Novartis and Pfizer Labs Limited as represented below in table 1 .

Table1. Target Population

\begin{tabular}{|l|l|l|}
\hline Strata Target & Population & Percentage \\
\hline Senior Management & 20 & $15.6 \%$ \\
\hline Middle Management & 30 & $23.4 \%$ \\
\hline Employees & 78 & $61 \%$ \\
\hline TOTAL & $\mathbf{1 2 8}$ & $\mathbf{1 0 0}$ \\
\hline
\end{tabular}

Source: Human resource department (2019)

The study adopted the census survey technique to select the respondents. This technique made it possible to incorporate all the 128 employees as it was seen to be a fairly manageable number to deal with, hence capturing all the relevant data to enable comparison of the strategies in place by these firms. With this method, all the 128 managers were involved in the survey.

Primary data was used for purposes of analysis. The research instrument used for the data collection was structured questionnaire. Use of structured questionnaires has been widely adopted in empirical studies (kinyua, Njoroge, Wanyoike\&Kiiru, 2015; Kiprotich, Kahuthia\& Kinyua, 2019; Makori\& Kinyua, 2019). To ensure the validity and reliability of the instrument, experts were consulted and a pilot study done and the Chronbach alpha coefficient tested respectively. The Chronbach alpha coefficients were used to determine if the content of the instrument were reliable enough to give consistent results. A Chronbach alpha coefficient of 0.7 and above indicates that the instrument is reliable enough for use (Criswell, 2014). The results of the Cronbach alpha coefficients is as presented in table 2:

Table2. Reliability Test

\begin{tabular}{|l|l|l|l|}
\hline Variable & Cronbach Alpha Index & Number of Items & Comment \\
\hline Competitive benchmarking & 0.744 & 4 & Reliable \\
\hline Service Delivery & 0.836 & 6 & Reliable \\
\hline Aggregate Score & $\mathbf{0 . 7 8 9}$ & $\mathbf{1 0}$ & Reliable \\
\hline
\end{tabular}

Source: Pilot Data (2020)

Findings in Table 2 indicate thatcompetitive benchmarking had a reliability of $(\alpha=0.744)$ while service delivery recorded a reliability coefficient of $(\alpha=0.789)$. The aggregate score of Cronbach alpha index for the 10 items related to the two variables was $(\alpha=0.789)$. From the table, all the variables of the study surpassed the 0.7 coefficient requirement provided by Gibson (2014) thus, they were reliable to be used in the study.

The collected primary data was filtered out and edited to make it relevant for analysis. Codes were given to the edited data, for ease of use during the analysis process by eliminating chances of errors 
being made. Statistical Package for Social Sciences (SPSS) version 25 software was then used to conduct both descriptive and inferential analysis. Results from the analysis were thereafter presented in forms of figures and tables. The inferential analysis sought to examine the effect of predictor variable, on the dependent variable as shown below.

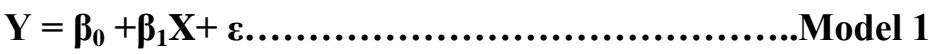

Where;

$\mathbf{Y}=$ Service Delivery

$\mathbf{X}=$ Competitive Benchmarking

$\boldsymbol{\beta}_{0}, \boldsymbol{\beta 1}$, = beta coefficients

$\boldsymbol{\varepsilon}=$ Error term

Simple linear regression analysis was conducted to establish the relationship between competitive benchmarking and service delivery of multinational pharmaceutical firms, Nairobi City County, Kenya. Analysis of Variance (ANOVA) was used to test the statistical significance of the model by indicating the probability of the occurrence of R2. The F-statistic in the ANOVA table was used to measure the fitness of the estimated regression model at $95 \%$ level of confidence where a p-value of at most 0.05 was used as the threshold for making the inference. A p-value of less than 0.05 was considered as the onset for establishing if the corresponding beta coefficient was statistically significant at a $95 \%$ level of confidence.

\section{RESEARCH FINDINGS AND DISCUSSION}

After administering 128 questionnaires to the respondents, the researcher was able to get back 104 which were well filled and qualified to be used for analysis. The 104 questionnaires represented a $81 \%$ response rate, which was sufficient enough to support the analysis to be conducted. According to Orodho (2014), a response rate of $70 \%$ and above suffices for drawing conclusions from.

\subsection{Descriptive Statistics}

The descriptive analysis results helped in making it easier to understand the distribution patterns of the data as well as indicating the level to which the respondents related with statements on external benchmarking and service delivery. The results for the descriptive analysis on competitive benchmarking is presented in table 2 .

Table1. Descriptive Statistics for Competitive Benchmarking

\begin{tabular}{|c|c|c|c|}
\hline Statements & $\sum^{0} \Xi$ & 苞 己े & 己 \\
\hline Competitive benchmarking improves the level of service delivery & 1.67 & 0.12 & 15 \\
\hline Comparing services/product offered by competitors impactsservice delivery. & 1.33 & 0.54 & 19 \\
\hline Use of responsiveness helps determine areas of improvements. & 1.35 & 0.62 & 21 \\
\hline $\begin{array}{l}\text { Understanding the processes of the pharmaceutical firms in other companies may } \\
\text { bring us new knowledge which may lead to further improved service delivery. }\end{array}$ & 1.38 & 0.47 & 14 \\
\hline Aggregate Index & 1.43 & 0.44 & 17 \\
\hline
\end{tabular}

Source: Survey Data (2020)

The descriptive statistics for competitive benchmarking indicate an aggregate mean of 1.43, standard deviation of 0.44 and coefficient variation of $17 \%$, approximating to agree on the Likert scale. The mean scores for the statements on the variable ranged from 1.67 as the highest and 1.33 as the lowest. On the other hand, the range of standard deviation was between 0.62 and 0.12 , while that of coefficient of variation was between 14 and $21 \%$. This low range of variation indicate that there was minimum variation of responses, relative to the mean and can therefore be relied upon. Therefore, it can be stated that competitive benchmarking was being practiced by the multinational pharmaceutical firms in Nairobi City County.

Table2. Descriptive statistics for service delivery

\begin{tabular}{|c|c|c|c|}
\hline Statements & $\sum_{\Sigma}^{\mathbb{J}}=$ & 完 ¿ & 己 \\
\hline Ease access of drugs by the consumers affect the service delivery of th & 1.67 & 0.12 & 16 \\
\hline
\end{tabular}


Analysis of The Role of Competitive Benchmarking on Service Delivery in Multinational Pharmaceutical Companies in Nairobi City County, Kenya

\begin{tabular}{|c|c|c|c|}
\hline pharmaceutical firms & & & \\
\hline $\begin{array}{l}\text { Implementation of service delivery measures is vital for the performance of } \\
\text { multinational pharmaceutical firms in Kenya }\end{array}$ & 1.33 & 0.54 & 14 \\
\hline $\begin{array}{l}\text { Efficiency of performance of multinational pharmaceutical firms is measured based on } \\
\text { modes of service delivery }\end{array}$ & 1.35 & 0.62 & 18 \\
\hline Adopting a follow-up survey is a better indicator of the nature of service provided & 1.38 & 0.47 & 22 \\
\hline $\begin{array}{l}\text { Service delivery in multinational pharmaceutical firms is a reflection on the levels of } \\
\text { consumers satisfaction }\end{array}$ & 1.58 & 0.31 & 21 \\
\hline Aggregate Index & 1.46 & 0.41 & 19 \\
\hline
\end{tabular}

Source: Survey Data (2020)

Presented in table 2 is the descriptive statistics for service delivery, as per the results, the aggregate mean, standard deviation and Coefficient of variation was $1.46,0.41$ and $19 \%$ respectively. The highest mean for the statements was 1.67 and the lowest was 1.33. As for the standard deviations, the highest and lowest value was 0.62 and 0.12 respectively. The range of the CV was between 14 and $22 \%$. The low variation in the coefficient of variations indicated that the responses did not vary a lot and the mean could be used to make generalization of the entire population of Multinational pharmaceutical firms in Nairobi City County, Kenya.

\subsection{Inferential Statistics}

Simple linear regression on the independent variable competitive benchmarking and the dependent variable service delivery was done. The simple linear regression analysis incorporated the ANOVA calculation together with the coefficient determination of $\left(\mathrm{R}^{2}\right)$ and finally the regression coefficients. Results of the multi-regression analysis are as shown below.

Table3. Model Summary

\begin{tabular}{|l|l|l|l|l|l|}
\hline \multicolumn{5}{|c|}{ Model Summary } \\
\hline Model & R & R Square & Adjusted R Square & Std. Error of the Estimate \\
\hline 1 & $.651^{\text {a }}$ & 0.423 & 0.413 & 0.651 \\
\hline
\end{tabular}

Source: Survey Data (2020)

The empirical model for competitive benchmarking and service delivery was found to be statistically significant. The results of the model summary showed that competitive benchmarking had variation in service delivery of multinational pharmaceutical firms in Nairobi City County, Kenya by $32.1 \%$. Consequently, the other factors not accounted for in this study explains the remaining $67.9 \%$ variation in the service delivery.

Table4. ANOVA Analysis

\begin{tabular}{|l|l|l|l|l|l|}
\hline \multicolumn{9}{|c|}{ ANOVA } \\
\hline Model 1 & Sum of Squares & Df & Mean Square & F & Sig. \\
\hline Regression & 15.511 & 8 & 5.470 & 14.368 & $.000^{b}$ \\
\hline Residual & 34.776 & 60 & .380 & & \\
\hline Total & 50.287 & 68 & & & \\
\hline
\end{tabular}

a. Dependent Variable: Service Delivery

b. Predictors: (Constant), Competitive Benchmarking

Source: Survey Data (2020)

The overall significance of the model was 0.000 which is less than 0.05 , this therefore indicated that competitive benchmarking was highly significant.

Table5. Coefficients

\begin{tabular}{|l|l|l|l|l|l|}
\hline \multicolumn{7}{|c|}{ Coefficients } \\
\hline & Unstandardized coefficients & Standardized coefficients & t & Sig \\
\hline & Beta & Std. error & Beta & & \\
\hline Constant & 1.313 & .445 & & & \\
\hline $\begin{array}{l}\text { Competitive } \\
\text { Benchmarking }\end{array}$ & .558 & .121 & .155 & 1.313 & .190 \\
\hline
\end{tabular}


Analysis of The Role of Competitive Benchmarking on Service Delivery in Multinational Pharmaceutical Companies in Nairobi City County, Kenya

a. Dependent variable: Service Delivery

b. Independent Variable: Competitive benchmarking

Source: survey (2020)

The results from table 5 above provide beta results for establishing the statistical model provided below:

\section{Service Delivery $=1.313+0.558$ Competitive Benchmarking}

From the model, it is established that when competitive benchmarking was constant, then service delivery of the multinational pharmaceutical firms stood at 1.313 unit. Additionally, the output presented by the findings from the regression analysis reveal that competitive benchmarking had a positive but insignificant effect on project performance with a $\beta_{2}=0.558, p=0.190$ and $\alpha=0.05$. 0.190 was more than 0.05 therefore indicating that it was not statistically significant. $\beta_{2}$ has a 0.558 effect on service delivery of pharmaceutical firms, though this effect was statistically insignificant.

The results differ by that conducted by (Oroo, 2017), which concluded by stating that competitive benchmarking effect on procurement performance of Naivas supermarket in Kisii County was significant. The findings do not concur with the RATER model which states that firms improve on their service delivery when they know where they stand in relation to their competitors in terms of reliability, assurance, empathy and responsiveness of their service which can be gauged by conducting competitive benchmarking. However, competitive benchmarking was established to have an effect on service delivery that was not statistically significant.

\section{CONCLUSION AND RECOMMENDATION}

The study aimed to determine the effect of competitive benchmarking on service delivery of multinational pharmaceutical firms in Nairobi City County, Kenya. Market penetration and market growth were used as indicators to measure competitive benchmarking. The results from the descriptive statistics analysis revealed a positive correlation between competitive benchmarking and service delivery. However, results of the simple linear regression established that competitive benchmarking was statistically insignificant. Given that the findings revealed competitive benchmarking as being statistically insignificant, no policy recommendations were made on it.

\subsection{Areas for Further Research}

The study was confined to competitive benchmarking and service delivery of multinational pharmaceutical firms in Nairobi City County, Kenya. Future researchers should therefore try and base their research on other industries and also assess other factors that could influence service delivery.

\section{REFERENCES}

[1] Abdullahi, m. o., student, m. b. a., \& Kinyua, g. total quality management practices and performance of Garissa county government, Kenya.

[2] Chorev, N. (2019). Give and Take: Developmental Foreign Aid and the Pharmaceutical Industry in East Africa. Princeton University Press.

[3] Creswell, J. W. (2014). A concise introduction to mixed methods research. SAGE publications.

[4] Elmuti, D. \&Kathawala, Y. (2012). An Overview of Benchmarking Process: a Tool for Continuous Improvement and Competitive Advantage. Benchmarking for Quality Management \& Technology, 4(4), 229-243

[5] Gabow, O. S., \& Kinyua, G. (2018). Relationship between Strategic Intent and Performance of Kenya Commercial Bank in Nairobi City County, Kenya. International Journal of Innovative Research and Advanced Studies, 5(11), 149-157.

[6] Hadland, S. E., Rivera-Aguirre, A., Marshall, B. D., \&Cerdá, M. (2019). Association of pharmaceutical industry marketing of opioid products with mortality from opioid-related overdoses. JAMA network open, 2(1), e186007-e186007.

[7] Karanja, E. W., Muraguri, C., \& Kinyua, G. (2018). Effects of teamwork on performance of the water service regulatory board. Strateg. J. Bus. Chang. Manag, 5, 1-6. 
[8] Kerandi, D., Nyaoga, R., Bosire, R., \&Nyambega, E. (2014). A survey of performance improvement through benchmarking in commercial banks in Kenya: The managers' perception and experience. International Journal of Business and Economics Research, 3(1), 6-14.

[9] King'oo, R. N., Kimencu, L., \& Kinyua, G. (2020). The Role of Networking Capability on Organization Performance: A Perspective of Private Universities in Kenya. Journal of Business and Economic Development, 5(3), 178-186.

[10] Kinyua, G. M., Njoroge, J. G., Wanyoike, R. W., \&Kiiru, D. M. (2015). Influence of Organization's Structure and Culture on Implementation of Strategies in Constituency Development Fund Board in Kenya. International Journal of Education and Research, 3(11), 209-218.

[11] Kinyua, M. N. (2014). Strategies adopted by multinational pharmaceutical firms in Kenya to respond to competitive rivalry in the pharmaceutical industry (Doctoral dissertation).

[12] Kiprotich, S. W., Kahuhia, J., \& Kinyua, G. (2019). An assessment of empirical rational strategy and normative re-educative strategy on organizational performance in public offices in Kenya: A case of Teachers Service Commission. International Academic Journal of Human Resource and Business Administration, 3(6), 93-117.

[13] Kobia, F. K., \& Kinyua, G. (2018). An Empirical Analysis of the Relationship between Product Development and Performance of Outlets of Bata Shoe Company in Nairobi City County, Kenya. International Journal of Innovative Research and Advanced Studies, 5(10), 55-60.

[14] Kumar, A. (2013). Analysis of Service Quality Using Servqual Model.

[15] Kung'u, S. M., Kahuthia, J., \& Kinyua, G. (2020). Analysis of the Effect of Strategic Direction on Performance of Motor Vehicle Assembly Firms in Nairobi City County, Kenya. International Journal of Managerial Studies and Research, 8(8), 2-94.

[16] Mailu, R. N., Ntale, J. F., \&Ngui, T. K. (2018). Strategy implementation and organizational performance in the pharmaceutical industry in Kenya. International Academic Journal of Human Resource and Business Administration, 3(2), 33-47.

[17] Makori, B. N., \& Kinyua, G. (2019). Organizational Leadership and performance of Co-operative Bank of Kenya. International Academic Journal of Human Resource and Business Administration, 3(5), 357-375.

[18] Mbugua, J. W., \& Kinyua, G. M. (2020). Service Differentiation and Organization Performance: An Empirical Analysis of Deposit Taking SACCOs in Nairobi City County, Kenya. Journal of Business and Economic Development, 5(2), 64-72.

[19] Muthoni, D. M., \& Kinyua, G. M. (2020). Corporate Reputation and Firm Performance: An Empirical Analysis of Motor Vehicle Assemblers in Nairobi City County, Kenya. Journal of Business and Economic Development, 5(2), 73-81.

[20] Oroo M, (2017). Assessment of factors affecting competitive benchmarking process on procurement performance; a case study of naivas supermarket, kisii branch.

[21] Ouma, A. M. (2018). Influence of value disciplines strategy on the management of efficiency levels in the pharmaceutical industry in Kenya (Doctoral dissertation, JKUAT).

[22] Ouma, J. (2014). Benchmarking Practices and Performance of Kenya Revenue Authority. MBA Project School of Business, University of Nairobi

[23] Saxena, M. A. (2011).Managing the new product development process: Strategic imperatives. The Academy of Management Executive, 12(3), 67-81.

[24] Tannoury, M., \&Attieh, Z. (2017). The influence of emerging markets on the pharmaceutical industry. Current therapeutic research, 86, 19-22.

[25] Twaissi, N. M., \&Alhelalat, J. A. (2015). Competitive benchmarking adoption issues in the hotel sector in Petra, Jordan. International Journal of Marketing Studies, 7(3), 53.

\section{AUTHORS' BIOGRAPHY}

Betty Mukiri Murerwa, is a logistics assistant in a pharmaceutical company. She has holds a Degree in Bachelor of Commerce in Purchasing and Business Logistics from Daystar University, Kenya. Currently pursuing a Degree in Master of Business Administration in Strategic Management from Kenyatta University. Her key areas of interest in research is global supply chain management. She has experience in procurement and logistics operations within the healthcare industry, in which she has 
become well versed in the procurement and logistics processes; including practical experience in management of inventory and sourcing of promotional and trade materials globally for the pharmaceutical industry.

Dr. Godfrey M. Kinyua, is a lecturer in the Department of Business Administration, School of Business of Kenyatta University. He holds a Doctor of Philosophy in Business Administration from Kenyatta University, Master of Business Administration from University of Nairobi and Bachelor of Education from Egerton University. His key area of interest in research include knowledge management, competitive intelligence and green innovation.

Citation: Betty Mukiri Murerwa, Godfrey Muigai Kinyua. "Analysis of The Role of Competitive Benchmarking on Service Delivery in Multinational Pharmaceutical Companies in Nairobi City County, Kenya" International Journal of Managerial Studies and Research (IJMSR), vol 9, no. 7, 2021, pp. 01-09. doi: https://doi.org/10.20431/2349-0349.0907001.

Copyright: () 2021 Authors. This is an open-access article distributed under the terms of the Creative Commons Attribution License, which permits unrestricted use, distribution, and reproduction in any medium, provided the original author and source are credited. 